\title{
Left-right coding in children: Implications for adult performance
}

\author{
CELIA B. FISHER \\ Fordham University, Bronx, New York 10458 \\ and \\ LILA G. BRAINE \\ Barnard College, Columbia University, New York, New York 10027
}

\begin{abstract}
Recent work with adults suggests that inferior performance on left-right (relative to up-down) tasks is not a perceptual difficulty but is tied to the use of spatial words. This interpretation rests on the assumption that preschool children have difficulty distinguishing between objects turned left or right and that spatial words are acquired at the time that children experience left-right confusion. However, this assumption is unwarranted in the light of recent work showing that 3-year-old children make left-right discriminations when stimuli are presented individually. This study pursues the problem further by asking whether left-right discriminations can be made in the dark, without any perceptual supports. Preschool children solved left-right (and up-down) problems in a few trials, demonstrating their ability to make left-right discriminations based solely on an egocentric frame of reference.
\end{abstract}

It has traditionally been reported that it is easier to identify the orientation of shapes that vary in the vertical dimension, up and down, than their left-right counterparts in the horizontal dimension (see review by Corballis \& Beale, 1976). The major theoretical explanation for this phenomenon, first proposed by Mach (1897) and later extended by, among others, Corballis and Beale (1976) and Nobel (1968), argues that the relative difficulty of left-right coding is rooted in the structure and function of organisms symmetrical about the vertical axis. Recently, however, the problem has taken a new turn. Maki and her colleagues (e.g., Maki, Grandy, \& Hauge, 1979) have found that the coding advantage of up-down over left-right appears only when the conventional spatial terms are used. A similar result has been reported for the identification of map locations (Sholl \& Egeth, 1981); that is, north-south identifications were easier than east-west identifications only when spatial terms were used. These findings have been interpreted as evidence that, in the adult, the locus of the left-right effect is at the verbal encoding, rather than at the perceptual encoding, stage (Maki et al., 1979; Sholl \& Egeth, 1981).

The research and preparation of this report was supported by the Fordham University Research Council, NIMH Grant IR03MH37431-01 to the senior author, and NICHD Grant HD-09513 to the junior author. We thank the children and staff of the Fieldston School for their cooperation, Carol Cornachia and Joan Engel for help with data collection, and Jonathan Galente for superb apparatus construction. Requests for reprints should be sent to Celia B. Fisher, Department of Psychology, Dealy Hall, Fordham University, Bronx, New York 10458.
To explain a verbal encoding basis for the left-right effect, investigators have looked to the developmental history of the organism. Traditionally, the literature has shown that young children have difficulty identifying and labeling left-right orientations of shapes (e.g., Benton, 1959; Over \& Over, 1967). Maki et al. (1979) suggest that "adults have trouble using the labels right and left because these labels are attached to two semantic concepts that are not very distinctive in memory . . . [because] the labels for horizontal concepts were acquired during childhood, when the problems of applying labels to these concepts were most acute" (p. 66). Sholl and Egeth (1981) suggest that "the difficulty adults experience when making horizontal judgments is most likely a vestige of the profound difficulty young children have in discriminating right from left" (p. 339). From this point of view, left-right difficulties stem from perceptual encoding processes in children and from lexical processes in adults.

A major difficulty with this interpretation is that the developmental literature no longer supports the view that preschool children cannot identify the left and right orientations of objects. Some years ago, various investigators found that the alignment of stimuli markedly affected the ease of making left-right discriminations; left-right discriminations were difficult when the stimuli were side by side, but easy when the stimuli were one above the other (e.g., Huttenlocher, 1967). Similar effects of alignment have been found with adults (e.g., Wolff, 1971). However, left-right discrimination under these conditions could be explained as due to subjects' matching analogous parts (Barroso \& Braine, 1974) rather than responding to a property of "leftness and 
rightness." Unequivocal evidence that the young child can make left-right identifications comes from a series of experiments by Fisher $(1979,1980)$ that demonstrate that it is task characteristics rather than an inability to tell left from right that are responsible for the poor performance of preschool children on a left-right problem. Fisher found that children as young as 3.5 years remembered left-right orientations with ease when figures were presented one at a time, although they failed the task when stimuli were presented side by side. The failure appeared to be due to the young child's reliance on configurational cues; that is, the child tends to judge the orientation of one figure in relation to the frame or to the other figure, and as the left-right positions of the stimuli change over trials, the configuration changes, disrupting the child's basis for judgment (Braine, 1978; Fisher, 1980). The developmental data thus suggest that the child's difficulty on left-right tasks is in using an appropriate spatial referent rather than in being unable to distinguish left-turned from right-turned.

Corballis and Beale (1976) have argued that evidence for the ability to code a shape as turned left or right must meet two requirements. First, discrimination must be evidenced under conditions in which the response required has an arbitrary relation to the spatial discrimination. Our previous research met this requirement: Children were trained to employ arbitrary labels to identify the left and right orientations of a figure. Moreover, the children generalized the labels to new figures not used in training, demonstrating that preschool children are able to abstract a general spatial attribute of leftness and rightness (Fisher \& Braine, 1981).

Corballis and Beale (1976) also stipulated that no environmental cues be available as a basis for making correct left-right judgments. For example, an asymmetric environment, such as a room with a door on the left side, might elicit a judgment that a shape was, or was not, turned toward the door. As long as an asymmetric cue remained visible during testing, reference to an internal spatial reference system would not be required. Our previous work did eliminate asymmetric environmental cues from the visible display by presenting the stimuli in circular frames viewed through the aperture of a display box. We wondered, however, whether the very presence of a visible world (provided by the visual frame itself or by occasional glances at the room between trials) might, in some way, facilitate the child's ability to make left-right identifications. The present experiment examines the preschool child's ability to use an egocentric spatial framework under very stringent conditions: The child sat in a light-tight chamber and viewed white outline figures projected onto a black wall. The figures looked as though they were floating in a dark, borderless space.

\section{METHOD}

\section{Subjects}

The subjects were nine males and seven females, with a mean age of 3 years 9 months (range $=3$ years 3 months to 4 years 3 months).

\section{Stimuli}

The stimuli were pictures of the side view of a dog and the front view of a jacket. With the dog picture, the left-right problem used an upright dog with its face turned to the left or right; the up-down problem used a dog with its face in either the 0 -deg or the 180 -deg position. With the jacket picture, the leftright problem used a jacket with one top rotated 90 deg to the left or right; the up-down problem used the jacket in either the 0 -deg or the $180-\mathrm{deg}$ position. The pictures were projected as white outline figures against a black background, and the long axis subtended a visual angle of $3.6 \mathrm{deg}$. Kodalith film was used for the slides.

\section{Apparatus}

The apparatus was a $29 \times 29 \times 58$ in. plywood box with one end open. It was lined with black felt and eliminated penetration and reflection of light. The box was positioned on a table. The subject, seated on an experimenter's lap, was positioned at the open end of the box under a hood that projected out from the box and excluded room light. The hood was sealed by a second experimenter after the child and adult were inside. The slides were projected onto the back wall through a small hole in the side of the box. The stream of light from the projector was blocked by a black plate.

\section{Procedure}

Prior to entering the testing chamber, the child was introduced to four dolls: teddy bear, lion, owl, and bunny. The child was told that the animals had some special pictures to show them in their house (the chamber was decorated on the outside with a Sesame Street sheet to make it less imposing). One experimenter sat in the chamber and invited the child in to sit on her lap. It was necessary to have the child on the experimenter's lap because our 3-year-olds would not enter the chamber themselves; in addition, the enclosed experimenter was able to check that no visible light intruded.

At the beginning of the first problem (left-right for half the subjects), the children were shown the figure to be discriminated and were instructed, "When the picture of the dog [or jacket] is turned like this [e.g., 90 deg left] you say 'teddy's way' because it's turned teddy bear's favorite way. Whenever the picture of the dog is turned like this [e.g., 90 deg right] you say 'lion's way' because it's turned lion's favorite way." After each trial, the subject was asked which way the figure was turned. The intertrial interval was $10 \mathrm{sec}$. Criterion was set at 9 of 10 consecutive trials correct or a maximum number of 26 trials. Subjects failing to reach criterion were given a score of 27. Immediately following the completion of the first orientation task, instructions were given for the second problem, and the child was told the new orientations of the second picture belonged to owl and bunny. The order of presentation of the problems and the animal names used to identify orientation were balanced across subjects.

\section{RESULTS AND DISCUSSION}

Thirteen of the 16 children tested learned both leftright and up-down problems and reached criterion very quickly. One child failed only the left-right problem, one child failed only the up-down problem, and one child failed both problems. For the left-right problem, children required an average of 13.5 trials to reach criterion (range $=9-21$ trials). For the up-down problem, children required an average of 9.8 trials to reach criterion (range $=9-11$ trials). Considering the performance of all 16 children, the difference between the problems was 
significant $[t(15)=2.25, \mathrm{p}<.05]$. One explanation for the relative difficulty of the left-right problem is that the identification of left and right always requires relating a feature of the shape to a framework, whereas up-down judgments can be made on simpler bases (Braine, 1978).

It is clear that these data replicate previous findings in showing that when stimuli are presented individually, young children do not confuse left and right. Even more important, the work confirms Fisher's earlier position (Fisher, 1979) that children can draw upon an internal frame of reference to make these judgments. Despite the fact that children can draw upon an egocentric frame of reference to code left and right, they apparently fail to do so when configurational cues are available, as discussed earlier. This finding is not unique, since configurational cues also dominate children's (and adults') judgments in other perceptual problems, such as the rod and frame task and induced motion (for a review, see Rock, 1975). Although children may show performance deficits on some left-right tasks, it is clear that even young preschool children possess considerable competence: They can see, label, and remember leftright orientation based only on an internal reference system. This conclusion has implications for general theories concerning the basis for left-right difficulties, and for the interpretation of adult performance on orientation tasks.

None of the traditional approaches to left-right difficulties offers a suitable explanation for the present and. related data. Clearly, the anatomical theory proposed by Corballis and Beale (1976) cannot account for the good performance reported here or for the effects of configurational cues in leading to poor performance in children. (Configurational cues may well impair adult performance, but investigations of this sort have yet to be done.) The view that children, and perhaps adults as well, do not attend to left-right differences in shapes because such information is not relevant, except for the alphabet (Gibson, 1969), does not explain the developmental data. Finally, although the present data do not speak to the notion that leftright is difficult because the ends of the horizontal dimension do not have clear referents (such as the sky and ground for the vertical dimension), several studies have shown that the horizontal dimension does not appear to be the essence of the left-right (or east-west) problem (Braine \& Eder, in press; Fisher, 1982; Maki et al., 1979; Sholl \& Egeth, 1981).

The notion that adult difficulties in spatial tasks are simply a vestige of childhood problems in identifying differences along the horizontal dimension seems implausible in the light of present evidence. It is abundantly clear that preschool children are able to make left-right discriminations and to assign arbitrary labels to these percepts. This ability is available before children usually begin to learn the words "left" and "right." In contrast to the view that left-right judgments are fundamentally different in the adult and in the preschool child, with perhaps a remnant of childish processing encoded in the semantic concepts associated with locative terms, we would argue for the fundamental similarity between adult and child judgments. Available to both are an internal reference system for making judgments and the ability to discriminate and to label differences between shapes turned left and right.

\section{REFERENCES}

Barroso, F., \& Braine, L. G. "Mirror-image" errors without mirror-image stimuli. Journal of Experimental Psychology, 1974, 18, 213-225.

Benton, A. L. Right-left discrimination and finger localization. New York: Hoeber-Harper, 1959.

Braine, L. G. A new slant on orientation perception. American Psychologist, 1978, 33, 10-22.

Braine, L. G., \& Eder, R. A. Left-right memory in two-yearold children: A new look at search tasks. Developmental Psychology, in press.

Corballis, M. C., \& Beale, I. L. The psychology of left and right. Hillsdale, N.J: Erlbaum, 1976.

Fishe R, C. B. Children's memory for orientation in the absence of external cues. Child Development, 1979, 50, 1088-1092.

Fisher, C. B. Children's memory for line orientation: A reexamination of the "oblique effect." Journal of Experimental Child Psychology, 1980, 29, 446-459.

Fisher, C. B. The role of stimulus alignment in children's memory for line orientation. Child Development, 1982, 53, 1070-1074.

Fisher, C. B., \& Braine, L. G. Children's left-right concepts: Generalizations across figure and location. Child Development, 1981, 52, 451-456.

Gibson, E. J. Principles of perceptual learning and development. New York: Appleton-Century-Croft, 1969.

HutTENLOChER, J. Discrimination of figure orientation: Effects of relative position. Journal of Comparative and Physiological Psychology, 1967, 63, 359-361.

Mach, E. The analysis of sensation. Chicago: Open Court Publishing, 1897.

Maki, R. H., Grandy, C. A., \& Hauge, G. Why is telling left from right more difficult than telling above from below? Journal of Experimental Psychology: Human Perception and Performance, 1979, 5, 52-67.

NoBLE, J. Paradoxical interocular transfer of mirror-image discrimination in the optic chiasm sectioned monkey. Brain Research, 1968, 10, 127-151.

Over, R., \& Over, J. Detection and recognition of mirrorimage obliques by young children. Journal of Comparative and Physiological Psychology, 1967, 64, 467-470.

Rock, I. An introduction to perception. New York: Macmillan, 1975.

Sholl, M. J., \& Egeth, H. E. Right-left confusion in the adult: A verbal labeling effect. Memory \& Cognition, 1981, 9, 339-350.

WolfF, P. Mirror-image confusability in adults. Journal of Experimental Psychology, 1971, 91, 268-272.

(Received for publication November 15, 1982.) 